\title{
Spectral characteristics of scintillations producing ionospheric irregularities in the Indian region
}

\author{
S. Banola ${ }^{1}$, B. M. Pathan ${ }^{1}$, D. R. K. Rao ${ }^{1}$, and H. Chandra ${ }^{2}$ \\ ${ }^{1}$ Indian Institute of Geomagnetism, Kalamboli Highway, New Panvel (W), Navi Mumbai 410218, India \\ ${ }^{2}$ Physical Research Laboratory, Navrangpura, Ahmedabad 380009, India
}

(Received February 4, 2004; Revised December 30, 2004; Accepted January 4, 2005)

\begin{abstract}
VHF amplitude scintillations were recorded at Tirunelveli $\left(8.7^{\circ} \mathrm{N}, 77.7^{\circ} \mathrm{E} ; 0.6^{\circ} \mathrm{N}\right.$ dip Latitude), Pondicherry $\left(12^{\circ} \mathrm{N}, 79.1^{\circ} \mathrm{E} ; 4.4^{\circ} \mathrm{N}\right.$ dip Latitude) and Mumbai, $\left(19^{\circ} \mathrm{N}, 73^{\circ} \mathrm{E} ; 13.5^{\circ} \mathrm{N}\right.$ dip Latitude) for the years $1992-1996$ using the $250 \mathrm{MHz}$ radio beacon from the geostationary satellite FLEETSAT $\left(73^{\circ} \mathrm{E}\right)$. The recorded digital scintillation data for few nights are analyzed to estimate scintillation index $\left(S_{4}\right)$, fade rates, auto-correlation functions and power spectral densities for every 2.5 minute sample during the period of the scintillation activity. The power spectral slopes are shallower for the scintillation at the generation phase and steeper towards the decay phase, which indicates the erosion of smaller scale sizes towards the decay phase.
\end{abstract}

Key words: Equatorial ionosphere, ionospheric irregularities, VHF Scintillation, fade rate.

\section{Introduction}

Nighttime equatorial F-region is a seat of intense plasma density irregularities encompassing scales from about 1000 $\mathrm{km}$ to a fraction of a meter. These plasma density irregularities are associated with the phenomenon of equatorial spread-F as seen in radio soundings of the ionosphere (occurrence of diffuse F-region traces in the ionograms), radio wave scintillation in trans-ionospheric propagation and radar backscatter at VHF/UHF. Reviews by Fejer and Kelley (1980), Kelley and McClure (1981), Ossakow (1981), Basu and Basu (1985) and Chandra (1990) cover the measurements and numerical simulation studies. It is now believed that a hierarchy of the processes is responsible for the generation of the irregularities at different scale sizes. It is well established now that large-scale plasma depletions are generated first in post-sunset period through Rayleigh-Taylor Instability and the depleted regions rise fast to cover the entire F region including topside ionosphere. Plasma processes then give rise to instabilities acting on the steep gradients available and generate smaller and smaller scale sizes in a cascade process (Haerendel, 1973). Since the equatorial spread-F irregularities extend along the field lines, higher the altitude of plasma depletion, wider the latitudinal extent of the irregularities.

Dungey (1956) suggested that the equatorial spread-F was initiated on the bottom-side F layer by Rayleigh-Taylor instability. Driven by meter-size irregularity distributions observed by ground-based radar and concurrent large-scale plasma holes measured 'in situ', theoretical efforts focussed on establishing various descriptions of spectral distributions over broad range of structures identified with spread-F. Initially it was thought that the planetary scale irregularities

Copy right(C) The Society of Geomagnetism and Earth, Planetary and Space Sciences (SGEPSS); The Seismological Society of Japan; The Volcanological Society of Japan; The Geodetic Society of Japan; The Japanese Society for Planetary Sciences; TERRAPUB. (owing to aeronomic effects and tidal waves) could cascade to $\mathrm{km}$ size dimensions, trigger the Rayleigh-Taylor Process and through a power law dependence distribute energy down to meter range. However, a cascade of energy from long to short wavelength could not explain observational results when Woodman and Basu (1978) extrapolated spectral behavior of (in-situ) medium to intermediate scale irregularities (100 m to $10 \mathrm{~km}$ ), down to Jicamarca VHF radar measurement size at $3 \mathrm{~m}$.

The trans-ionospheric signal scintillation causes considerable communication hazards at a wide range of frequencies and hence is of much practical interest (Banerjee et al., 1992). Earlier studies of the scintillation phenomenon indicated that it is more frequent and intense at latitudes around the magnetic equator and in the auroral zone (Aarons, 1982). Most of the long-term observations of scintillation have been carried out close to the magnetic equator in African and American sectors (Taur, 1973; Aarons, 1982; Rastogi, 1982; Basu and Basu, 1985). Short-term studies in the Indian sector also exist (Krishnamorthy et al., 1979; Chandra et al., 1979; Rastogi et al., 1982; Pathan et al., 1991). Using recent theoretical and experimental investigations, it can be inferred that the equatorial F-region plasma within an entire flux tube becomes unstable and hence the irregularity belt extends to thousands of km north and south of the magnetic equator (Anderson and Haerendel, 1979).

A network of nearly 20 stations was established in India under the All India Coordinated Programm of Ionospheric and Thermospheric Studies (AICPITS). The chain covering latitudes from the magnetic equator to beyond the anomaly crest region, recorded scintillation at $244 \mathrm{MHz} / 250 \mathrm{MHz}$ using radio beacon on-board FLEETSAT in order to study temporal and spatial variations of scintillation. As part of the coordinated studies, first campaign was conducted during March-April 1991. It was observed that scintillations occur in a continuous patch or in patches of longer dura- 
tion near the magnetic equator, while away from the equator there is a systematic delay in its onset and they occur in smaller patches with a smaller duration (Chandra et al., 1993). Third campaign was conducted during FebruaryMarch 1993 (Sushil Kumar et al., 2000). The variations of the onset time of scintillation with latitude were studied from average nocturnal variations of the percentage occurrence of scintill ation during the campaign period based on quarter-hourly values. The vertical velocity of the plasma depletions was estimated from time delays between the monthly mean onset time of scintillation at locations centered at 0, 10, 20, 30 and 40? dip angles. The altitudes at dip equator corresponding to the field lines at $300 \mathrm{~km}$ at locations of 10, 20, 30 and 40? dip are about 365, 550, 850, and $1350 \mathrm{~km}$ respectively. The velocities were found to be $40,420,330$ and $140 \mathrm{~m} / \mathrm{s}$ for the altitude regions 300-365, $365-550,550-850$ and $850-1350 \mathrm{~km}$ respectively.

Employing the VHF scintillation as means of understanding the ionospheric irregularities, the latitudinal progression of the 'spectral characteristics' are examined and the results are reported in this communication. For this, the digital scintillation recordings were made at Tirunelveli, Pondicherry and Mumbai (Bombay) at a sampling of $10 \mathrm{~Hz}$. For the comparative study, care has been taken in choosing the nights of scintillation activity so that the ionospheric irregularity was first observed in the vicinity of the magnetic equator and later at latitudes away from equator.

\section{Observations}

Amplitude scintillation on $250 \mathrm{MHz}$ signal from geostationary satellite FLEETSAT have been regularly monitored at a number of stations extending from magnetic equator to about $30^{\circ} \mathrm{N}$ dip in the Indian zone for the last decade. The receiving system consists of a simple eleven-element Yagi-Udi Antenna, an indigenously fabricated VHF Receiver and a recording unit. Digital data were recorded with sampling rate of $10 \mathrm{~Hz}$ at equatorial station, Tirunelveli ( $0.6^{\circ} \mathrm{N}$ dip Latitude), Pondicherry ( $4.4^{\circ} \mathrm{N}$ dip Latitude), a station at the fringe of the daytime equatorial electrojet and Mumbai (Bombay $13.5^{\circ} \mathrm{N}$ dip Latitude), a station south of the anomaly crest region for the years 1992-96. Figure 1 shows the map of observational sites with their subionospheric points at $400 \mathrm{~km}$. Only nighttime scintillation that are associated with F-region ionospheric irregularities have been considered in this communication. The recorded VHF scintillations are analyzed to estimate scintillation indices $\left(S_{4}\right)$, fa de rates, autocorrelation functions and power spectral densities for each of the 2.5 minute interval during the period of the activity for the comparative study at the stations for the following selected nights,

(i) 21 September 1992-Tirunelveli

(ii) 28 December 1992-Tirunelveli \& Mumbai

(iii) 3 April 1993 - Tirunelveli \& Mumbai

(iv) 11 June 1993-Tirunelveli \& Mumbai

(v) 26 March 1994-Tirunelveli \& Mumbai

(vi) 14 September 1994-Tirunelveli \& Mumbai

(vii) 2 October 1994-Pondicherry \& Tirunelveli

(viii) 14 December 1994-Tirunelveli, Pondicherry \& Mumbai

(ix) 30 January 1995-Pondichery \& Mumbai

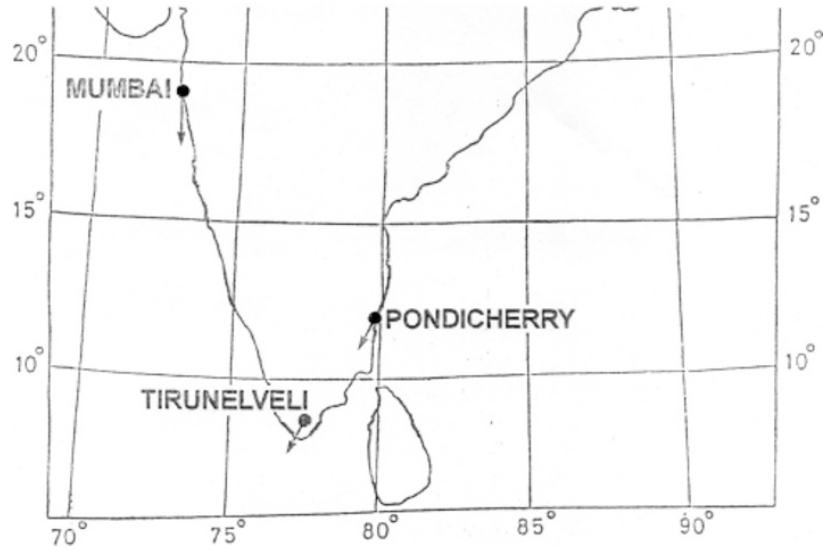

Fig. 1. Map showing the positions of the observational sites with their sub-ionospheric points at $400 \mathrm{~km}$ height.

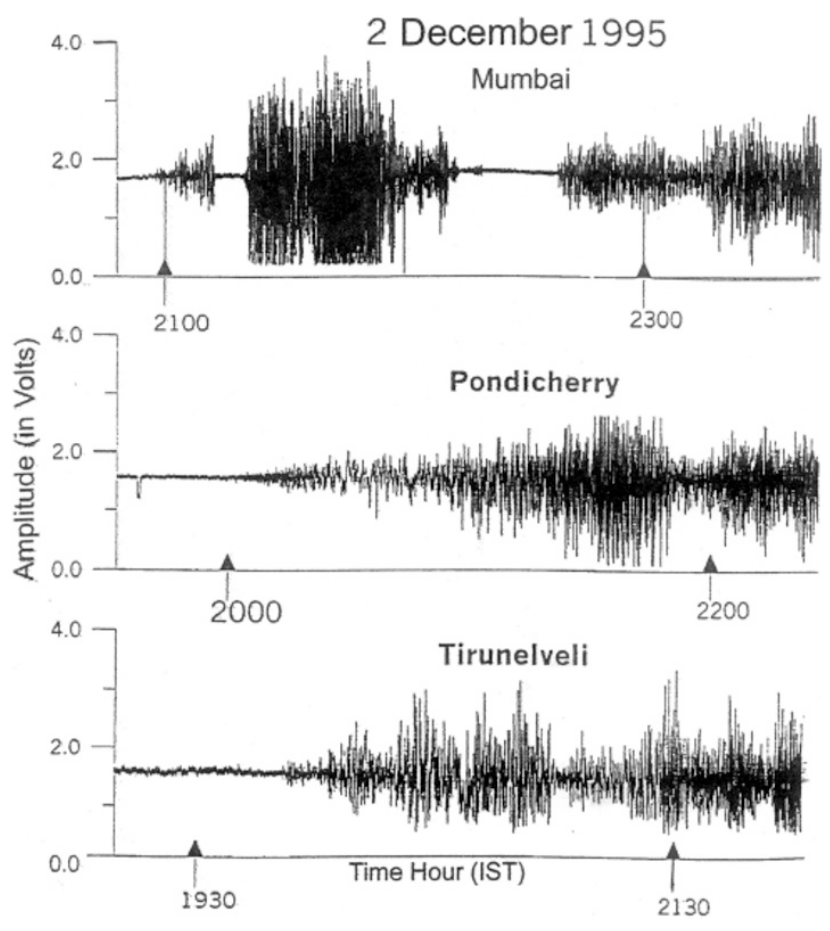

Fig. 2. Examples of Scintillation onset on 2 December 1995 for Tirunelveli, Pondicherry and Mumbai (Bombay).

(x) 2 December 1995-Tirunelveli, Pondicherry \& Mumbai

(xi) 21 December 1995-Tirunelveli \& Mumbai

(xii) 19 October 1996-Tirunelveli \& Mumbai

Examples of the onset of scintillation recorded at Tirunelveli, Pondicherry and Mumbai (Bombay) on the night of 2 December 1995 are shown in Fig. 2. Only recordings in the vicinity of the onset times are included at each of the stations. Scintillation was first observed at Tirunelveli at $1959 \mathrm{~h}$ local time $\left(82.5^{\circ} \mathrm{EMT}\right)$, at $2001 \mathrm{~h}$ at Pondicherry and at $2058 \mathrm{~h}$ at Mumbai. Scintillations are seen continuously from $1959 \mathrm{~h}$ to $0404 \mathrm{~h}$ at Tirunelveli, in two patches (during 2001-0219 h and 0233-0238 h) at Pondicherry and in three patches (2058-2112 h, 2119-2213 h and 2236-0233 h) at Mumbai. Scintillations at equatorial stations (Tirunelveli or Pondicherry) were normally observed in continuous patches 
whereas scintillations at Mumbai appear in comparatively more distinct patches and are of shorter durations.

\section{Results}

\subsection{Power spectrum and autocorrelation analysis}

To quantify the amplitude scintillation, it is necessary to assign an index, which can characterize the degree to which a signal is scintillating. The output of the receiver is normally proportional to the amplitude of the wave received from the antenna. The commonly used $S_{4}$ index (Briggs and Parkin, 1963) which is the Normalized root mean square deviation of power, is given by

$$
S_{4}=\left[\left\langle R^{2}-\left\langle R^{2}\right\rangle\right\rangle\right]^{1 / 2} /\left\langle R^{2}\right\rangle
$$

where, $R$ and $R^{2}$ are the instantaneous amplitude and power of the received signal and $\left\langle R^{2}\right\rangle$ indicate the average, which are scaled from the records on the nights chosen.

Power spectrum of scintillation events contains information about the spectral content of irregularities causing scintillation. Power spectrum is computed for every 5 minutes of data interval (3000 data points) via FFT using the standard software routine. The roll-off and 'Fresnel' frequencies have been identified for each of the individual spectrum computed. This is felt a better method of comparison of spectral slopes and de-correlation distances between stations. Autocorrelation analysis is another way of characterizing the scintillation fading. It is also an effective means of achieving time diversity improvements. Autocorrelation interval is defined as the time lag for which the level of correlation of the signal decreases to $50 \%$ of its maximum value (Umeki et al., 1977). The correlation interval multiplied by the velocity transverse to the ray path would provide the de-correlation distance on the ground. The ground decorrelation distance obtained from the correlation interval can be used for required antenna diversity. Also by taking the inverse of the $50 \%$ correlation time, average fading rate can be estimated.

Scintillation event observed at Tirunelveli on 2 December 1995 during pre-midnight hours is shown in Fig. 3I(a) with autocorrelation function and power spectrum in Figs. 3I(b), (c). The autocorrelation function is plotted up to 80 lags (Fig. 3I(b)). Closely following Umeki et al. (1977), it is observed that the correlation interval to be 14 lags $(1.4 \mathrm{~s})$ from Fig. 3I(b). Slope ' $\mathrm{m}$ ' is estimated from linear high frequency roll-off portion of log-log plot of power versus frequency shown in Fig. 3I(c) by fitting a straight line to the steepest part using least square technique, the portion selected is shown by two vertical dotted lines in the figure. Slope $m$ works out to be -2.7 . Fresnel frequency is estimated from the center of the broad maxima and the ground decorrelation distance is calculated by multiplying the autocorrelation interval $(t)$ with the transverse drift speed $(V)$ as given in Table 1. Transverse drift speed $(V)$ is calculated from the Fresnel frequency following Rufenach (1972)

$$
f_{F}=V /(\pi \lambda Z)^{1 / 2}
$$

where

$Z=$ effective distance of irregularity layer from receiver $\lambda=$ signal wavelength.
TIRUNELVELI 2 DECEMBER 1995
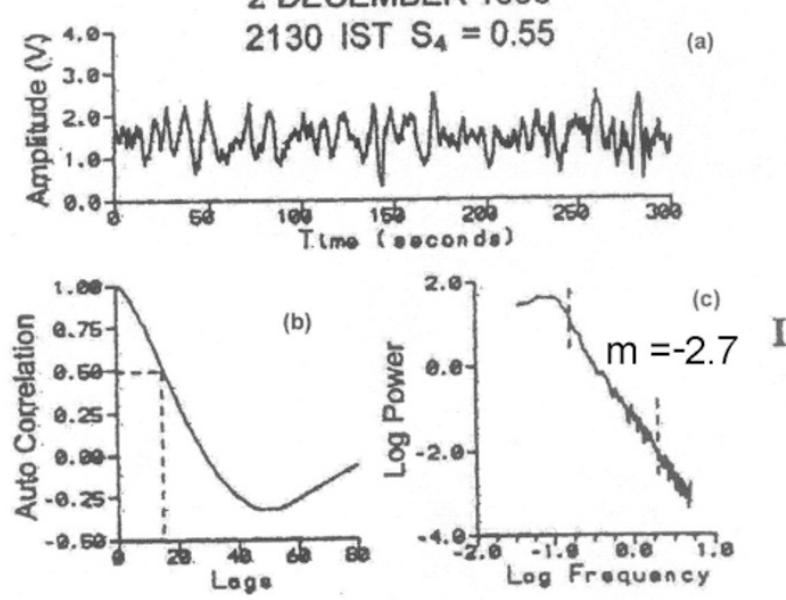

PONDICHERRY

2 DECEMBER 1995
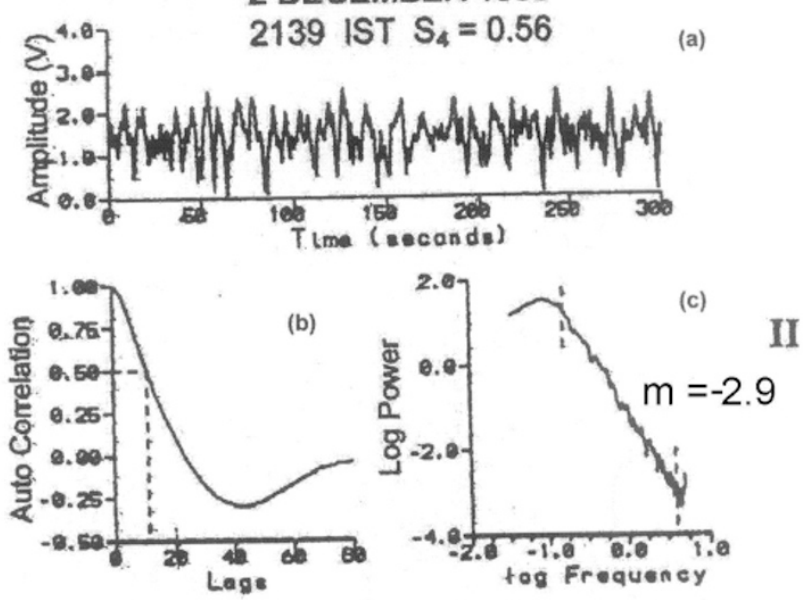

MUMBAI

\section{DECEMBER 1995}
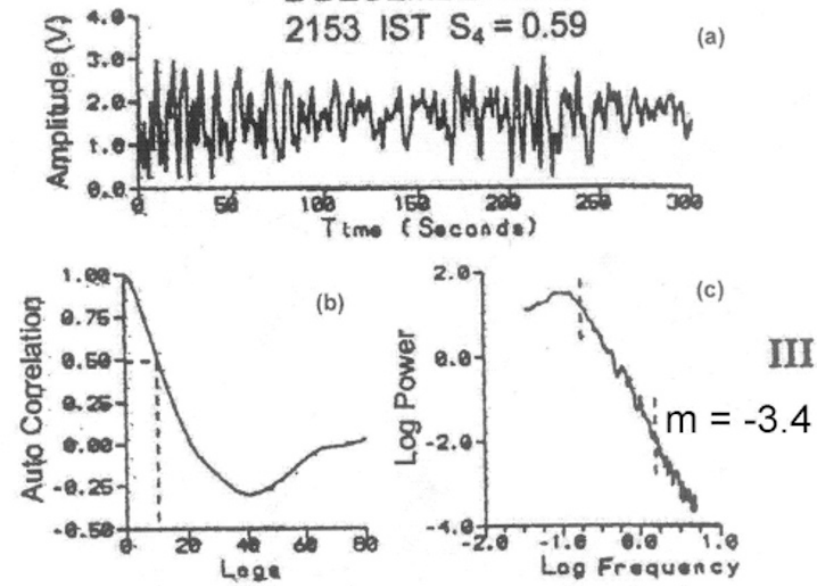

Fig. 3. I: 5 minute sample of scintillations observed on 2 December 1995 at $2130 \mathrm{~h}$ at Tirunelveli with autocorrelation coefficients upto 80 lags and corresponding power spectrum. II: Same as Fig. 3I but for Pondicherry at 2139 h. III: Same as Fig. 3I but for Mumbai at 2153 h.

Figures 3II and 3III show similar results for Pondicherry and Mumbai respectively. The autocorrelation intervals and spectral slopes are $1.1 \mathrm{~s}$ and -2.9 for Pondicherry and $1 \mathrm{~s}$ 
Table 1. Parameters obtained from power spectrum and autocorrelation analysis of the events.

\begin{tabular}{|c|c|c|c|c|c|c|c|}
\hline Station & $\begin{array}{l}\text { Time } \\
\text { (IST) }\end{array}$ & $\begin{array}{c}S_{4} \\
\text { Index }\end{array}$ & $\begin{array}{l}\text { Slope } \\
\text { (m) }\end{array}$ & $\begin{array}{c}\text { Fresnel } \\
\text { Freq. (Hz) }\end{array}$ & $\begin{array}{c}\text { Transverse } \\
\text { Drift Speed } \\
\text { V }(\mathrm{m} / \mathrm{s})\end{array}$ & $\begin{array}{c}\text { Autocor. } \\
\text { Interval } \\
\mathrm{T}(\mathrm{sec})\end{array}$ & $\begin{array}{c}\text { Decor. Dist. } \\
\text { VXT (m) }\end{array}$ \\
\hline \multicolumn{8}{|l|}{14 Dec., 1994} \\
\hline Tirunelveli & 2034 & .54 & -3.2 & 0.12 & 118.5 & 1.6 & 188.4 \\
\hline Pondicherry & 2106 & .46 & -3.2 & 0.10 & 98.9 & 1.7 & 164.3 \\
\hline Mumbai & 2146 & .63 & -3.3 & 0.10 & 101.8 & 0.8 & 84.5 \\
\hline \multicolumn{8}{|l|}{2 Dec., 1995} \\
\hline Tirunelveli & 2130 & .55 & -2.7 & 0.07 & 69.1 & 1.5 & 103.7 \\
\hline Pondicherry & 2139 & .56 & -2.9 & 0.08 & 79.2 & 1.2 & 90.3 \\
\hline Mumbai & 2153 & .59 & -3.4 & 0.07 & 71.3 & 1.0 & 72.7 \\
\hline \multicolumn{8}{|l|}{30 Jan., 1995} \\
\hline Pondicherry & 2308 & .55 & -3.8 & 0.09 & 89.1 & 1.3 & 114.0 \\
\hline Mumbai & 2327 & .25 & -4.2 & 0.04 & 40.7 & 1.7 & 67.6 \\
\hline
\end{tabular}

Table 2. Percentiles for fade rates for pre-midnight and post-midnight on ten selected nights

\begin{tabular}{|c|c|c|c|c|c|c|c|}
\hline \multirow[t]{2}{*}{ Date } & \multirow[t]{2}{*}{ Station } & \multicolumn{3}{|c|}{ Pre-midnight } & \multicolumn{3}{|c|}{ Post-midnight } \\
\hline & & $\mathrm{L}(\mathrm{Q} 1)$ & MED & $\mathrm{U}(\mathrm{Q} 3)$ & $\mathrm{L}(\mathrm{Q} 1)$ & MED & U(Q3) \\
\hline \multirow[t]{2}{*}{$3-4-93$} & Tirunelveli & 8 & 10 & 14 & 6 & 8 & 13 \\
\hline & Mumbai & 8 & 9 & 12 & 5 & 8 & 11 \\
\hline \multirow[t]{2}{*}{$11-6-93$} & Tirunelveli & 10 & 12 & 15 & 10 & 11 & 14 \\
\hline & Mumbai & 8 & 10 & 13 & 7 & 9 & 12 \\
\hline \multirow[t]{2}{*}{$26-3-94$} & Tirunelveli & 11 & 14 & 19 & & No data & \\
\hline & Mumbai & 30 & 46 & 65 & 11 & 15 & 29 \\
\hline \multirow[t]{2}{*}{$14-9-94$} & Tirunelveli & 8 & 11 & 14 & 11 & 16 & 25 \\
\hline & Mumbai & 7 & 10 & 13 & 5 & 14 & 22 \\
\hline \multirow[t]{2}{*}{$2-10-94$} & Tirunelveli & 6 & 10 & 13 & 4 & 6 & 7 \\
\hline & Pondicherry & 6 & 10 & 12 & 6 & 8 & 11 \\
\hline \multirow[t]{3}{*}{$14-12-94$} & Tirunelveli & 9 & 10 & 11 & 11 & 12 & 15 \\
\hline & Pondicherry & 10 & 12 & 15 & 13 & 15 & 17 \\
\hline & Mumbai & 14 & 20 & 25 & 12 & 15 & 18 \\
\hline \multirow[t]{2}{*}{$30-1-95$} & Pondicherry & 11 & 12 & 15 & 7 & 9 & 14 \\
\hline & Mumbai & 11 & 12 & 15 & 7 & 8 & 13 \\
\hline \multirow[t]{3}{*}{$2-12-95$} & Tirunelveli & 7 & 10 & 14 & 7 & 10 & 11 \\
\hline & Pondicherry & 10 & 12 & 15 & 10 & 13 & 19 \\
\hline & Mumbai & 8 & 9 & 17 & 5 & 7 & 9 \\
\hline \multirow[t]{2}{*}{$21-12-95$} & Tirunelveli & & No date & & 5 & 10 & 17 \\
\hline & Mumbai & & No date & & 6 & 7 & 8 \\
\hline \multirow[t]{2}{*}{$19-10-96$} & Tirunelveli & 10 & 11 & 15 & 8 & 10 & 12 \\
\hline & Mumbai & 7 & 10 & 13 & 6 & 9 & 12 \\
\hline
\end{tabular}

and -3.4 for Mumbai. As power spectra are Fourier Transform of autocorrelation function, absence of short period structures in autocorrelation function leads to lesser power in high frequency part of power spectrum. The range of frequencies over which spectral slope is calculated at different stations is necessarily different, as a result of shift in roll-off frequency. For the estimated transverse drift speeds, these frequency ranges translate into irregularity wavelength.

In Fig. 4, mass plots of $S_{4}$ indices, fade rates, autocorrelation intervals and spectral slopes are shown for every 2.5 minute data interval at each of the stations on the night of
2-3 December 1995. From figure it is evident that a large scatter of values persists at all the stations. To understand the behavior of spectral slopes, fade rates and $S_{4}$ index at different latitude and phases of progression of the activity, pre-midnight and post-midnight times, percentiles (median, lower and upper quartiles, instead of mean and standard deviation) are calculated for ten different cases separately for pre-midnight (18 to $00 \mathrm{~h}$ ) and post-midnight (00 to $06 \mathrm{~h}$ ). The values for fade rates, spectral slopes and $S_{4}$ index are listed in Tables 2, 3 and 4 respectively.

We notice from Table 2 that one sample in pre and an- 
Table 3. Percentiles for spectral slopes for pre-midnight and post-midnight on ten selected nights.

\begin{tabular}{|c|c|c|c|c|c|c|c|}
\hline \multirow[t]{2}{*}{ Date } & \multirow[t]{2}{*}{ Station } & \multicolumn{3}{|c|}{ Pre-midnight } & \multicolumn{3}{|c|}{ Post-midnight } \\
\hline & & L(Q1) & MED & U(Q3) & L(Q1) & MED & $\mathrm{U}(\mathrm{Q} 3)$ \\
\hline \multirow[t]{2}{*}{$3-4-93$} & Tirunelveli & -2.2 & -2.4 & -2.9 & -2.3 & -2.9 & -3.3 \\
\hline & Mumbai & -2.6 & -2.8 & -3.0 & -2.8 & -3.2 & -3.5 \\
\hline \multirow[t]{2}{*}{$11-6-93$} & Tirunelveli & -2.1 & -2.5 & -3.0 & -2.3 & -2.8 & -3.5 \\
\hline & Mumbai & -2.8 & -2.9 & -3.5 & -2.9 & -3.2 & -3.9 \\
\hline \multirow[t]{2}{*}{$26-3-94$} & Tirunelveli & -2.8 & -3.4 & -3.7 & & No data & \\
\hline & Mumbai & -2.2 & -2.9 & -3.4 & -2.7 & -3.2 & -2.3 \\
\hline \multirow[t]{2}{*}{$14-9-94$} & Tirunelveli & -2.1 & -2.5 & -3.1 & -1.9 & -2.3 & -3.0 \\
\hline & Mumbai & -2.9 & -3.7 & -4.2 & & No Scnt. & \\
\hline \multirow[t]{2}{*}{$2-10-94$} & Tirunelveli & -2.5 & -2.8 & -3.1 & -2.2 & -2.6 & -3.0 \\
\hline & Pondicherry & -3.1 & -2.8 & -3.5 & -2.3 & -3.2 & -3.7 \\
\hline \multirow[t]{3}{*}{$14-12-94$} & Tirunelveli & -2.6 & -2.9 & -3.2 & -2.5 & -2.9 & -3.4 \\
\hline & Pondicherry & -2.5 & -2.8 & -3.1 & -2.9 & -3.0 & -3.4 \\
\hline & Mumbai & -3.2 & -3.5 & -3.9 & -2.5 & -3.0 & -3.4 \\
\hline \multirow[t]{2}{*}{$30-1-95$} & Pondicherry & -3.1 & -3.7 & -3.8 & -1.9 & -2.5 & -2.4 \\
\hline & Mumbai & -2.6 & -3.0 & -3.4 & -2.1 & -2.7 & -2.1 \\
\hline \multirow[t]{3}{*}{$2-12-95$} & Tirunelveli & -2.7 & -3.0 & -3.6 & -2.5 & -2.9 & -3.5 \\
\hline & Pondicherry & -2.8 & -3.3 & -3.9 & -2.5 & -3.3 & -4.1 \\
\hline & Mumbai & -4.3 & -4.7 & -5.2 & -2.6 & -3.2 & -4.0 \\
\hline \multirow[t]{2}{*}{$21-12-95$} & Tirunelveli & & No data & & -1.9 & -2.2 & -2.6 \\
\hline & Mumbai & & No data & & -2.5 & -2.9 & -2.9 \\
\hline \multirow[t]{2}{*}{$19-10-96$} & Tirunelveli & -2.5 & -3.1 & -3.5 & -2.7 & -3.3 & -3.8 \\
\hline & Mumbai & -4.1 & -4.5 & -4.9 & -4.3 & -4.7 & -5.1 \\
\hline
\end{tabular}

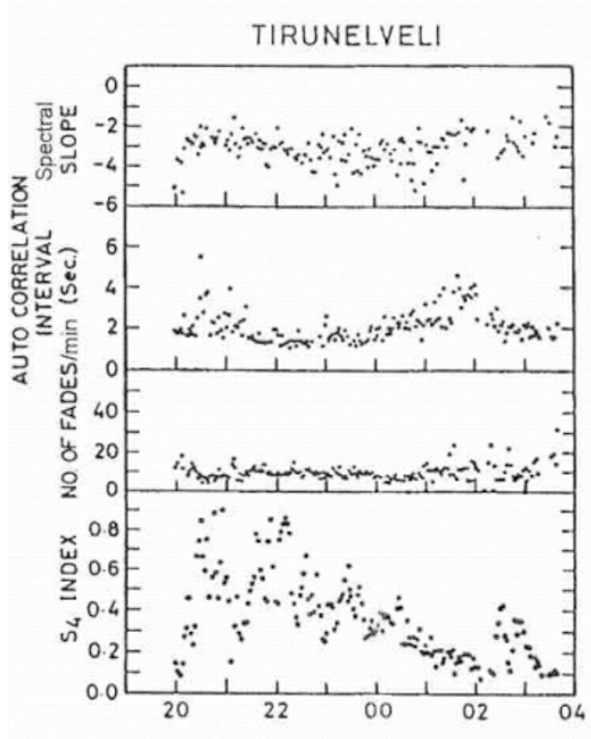

2 DECEMBER 1995 PONDICHERRY
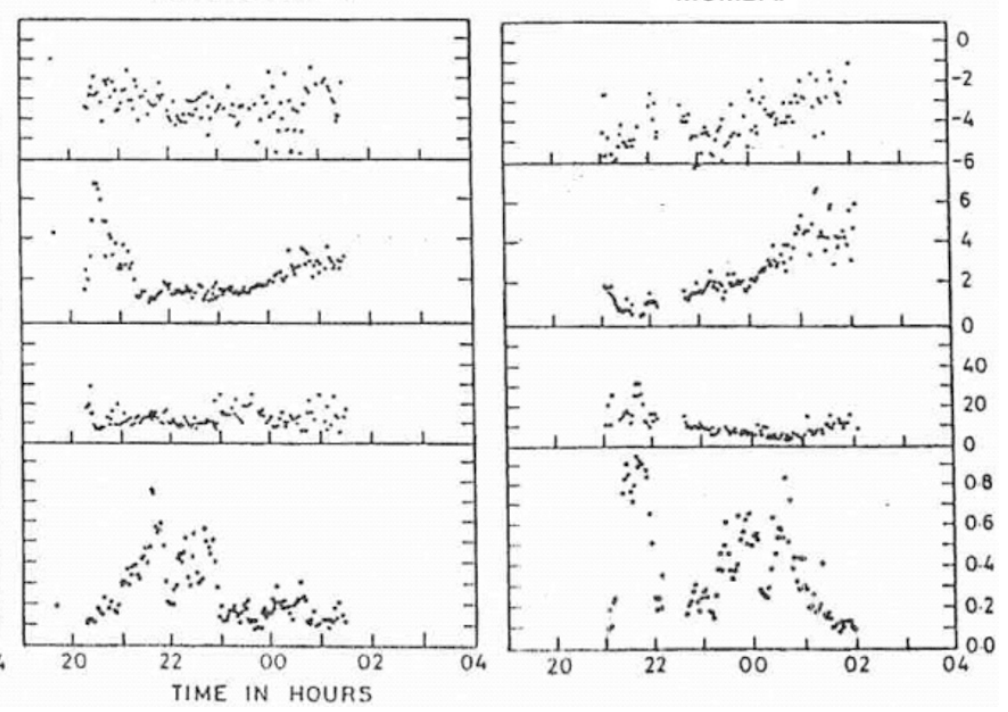

Fig. 4. Mass plots at the three stations at every 2.5 minute data interval of (i) $S_{4}$ indices (ii) fade rates (iii) autocorrelation intervals and (iv) spectral slopes for 2/3 December 1995 night.

other in post midnight have no data. So there are 5 cases out of 8 (3-4-93, 11-6-93, 14-9-94, 2-12-95, and 19-10-96) for which the fade rates (median values) for equatorial region are higher than those at Mumbai in pre-midnight. There are 6 cases out of 8 (11-6-93, 14-9-94, 30-1-95, 2-12-95, 21-12-95 and 19-10-96) for which the fade rates (median values) for equatorial region are higher than those at Mumbai in post-midnight. It is clear from these results that for equatorial region (for both pre-midnight and post midnight), the fade rates are relatively higher than those at Mumbai. Thus fade rate decreases with increase in the latitude. It appears from Table 2, that the median fade rate for post- 
midnight is less than that of pre-midnight (for 6 out of 9 cases, 3-4-93, 11-6-93, 2-10-94, 30-1-95, 19-10-96 and 263-94. At Rajkot fading rate decreases from 120 fades/min in pre-midnight to 20 fades/min in post midnight (Pathak et al., 1995). At Mumbai on 26 March 1994 fade rate of up to 118 fades/min was noticed whereas on other stations it varies up to 50 fades/min.

From Table 3, in 3 cases no data or no scintillation does not allow comparison, so out of 7 cases only for 3 cases (34-93, 11-6-93 and 19-10-96) post-midnight spectral slopes were marginally higher at all 3 latitudes when compared to pre-midnight indicating the faster decay of shorter wavelength irregularities first at all the latitudes. In Table 3, in 6 cases out of 9 (3-4-93, 11-6-93, 14-9-94, 14-12-94, 2$12-95$ and 19-10-96) for pre-midnight and 6 cases out of 9 (3-4-93, 11-6-93, 2-10-94, 30-4-95, 21-12-95 and 19-1096) for post-midnight, the spectral slope values increase from equatorial station to Mumbai. From 10 different mass plots, we observe that auto-correlation intervals are found significantly higher during the post-midnight period at Mumbai as compared to equatorial stations (Tirunelveli and Pondicherry). Autocorrelation interval increases with latitude. As expected autocorrelation interval also decreases with increase of the irregularity drift speed as listed in Table 1 . It also decreases with increase of $S_{4}$ index.

From the different mass plots like Fig. 4, we observe that the power spectral slopes are shallower for scintillation at the generation phase of the activity and steeper toward the decay phase, which indicates the erosion of smaller scale sizes towards the decay phase. From Fig. 5 it may be concluded that the fade rates are definitely higher during the evolution phases at Tirunelveli and Pondicherry on 2 October 1994 and at Mumbai on 2 December 1995 and 14 December 1994. In case of other occasions, it is not very clear from mass plots. Similarly, higher $S_{4}$ indices during evolution phases are very clear at all the three stations on 2 December 1995 and only at Mumbai on 14 December 1994. However on 2 October 1994, $S_{4}$ indices are not higher during evolution phase of the activity either at Tirunelveli or at Pondicherry. From the mass plots, Table 4 shows $S_{4}$ indices for pre-midnight and post-midnight on 9 selected nights. In Table 4 for 6 cases out of $8, S_{4}$ index (medi an values) are higher for equatorial region than Mumbai for pre-midnight (except 14-12-94 and 19-10-96) whereas in 6 cases out of 8 (except 28-12-92 and 14-12-94), $S_{4}$ index (median values) are higher for equatorial region than Mumbai for post-midnight. Hence $S_{4}$ index values decrease with increase in the latitude. For 7 cases out of 9, median $S_{4}$ index for post-midnight is less than that of pre-midnight (except 28-12-92 and 19-10-96). It is observed that the premidnight $S_{4}$ index is always higher when compared with post-midnight indices.

\subsection{Role of $S_{4}$-index and fade rate in determining the} spectral shapes

To determine this relationship, we have used Tirunelveli and Mumbai data for 1992 and 1999 at different $S_{4}$ indices and fade rates. The three criteria adopted for the selected cases are i. When $S_{4}$ at Tirunelveli at two different times are same but fade rates are different (27 March 1999).

ii. When $S_{4}$ at Tirunelveli at two different times are different but fade rate is almost the same (21 September, 1992).

iii. When $S_{4}$ and fade rate both at the two stations Tirunelveli and Mumbai are same (28 December, 1992).

For the first case on 27 March 1999, $S_{4}$ indices are identical (1.0 and 1.03) but fade rates are differing widely (17 and 28 fades/minute) at Tirunelveli as shown in the top two panels in Fig. 6. Third panel shows spectra for the two different intervals, which are differing considerably. In the second case on 21 September 1992, $S_{4}$ indices are different $(0.76$ and 1.14) whereas fade rates are same (15 fades/minute) as shown in Fig. 7. Here the spectral shapes of the two spectra are nearly the same with values of -3.4 and -3.6 respectively. In the last case on 28 December 1992 (Fig. 8) when both $S_{4}$ indices and fade rates are same $\left(S_{4}=0.96\right.$ and 1.01; fade rate $=8$ and 7) shapes of spectra are coinciding with each other. Also, in this case up to roll-off frequency both curves are exactly overlapping and after that only slight variations are observed.

\section{Inferences}

From the above three cases, it can be inferred that the fade rate plays a major role in determining the shape of the spectrum. If fade rates are the same, spectra are overlapping, otherwise they are differing considerably. This indicates that the ionospheric irregularity structure through which radio wave is traversing to produce scintillation pattern on the ground, is of primary importance rather than the generation, rate of uplift or its diffusion to higher latitudes. As it is well known to have ionospheric irregularity both $\Delta n_{e}$ (variation in the density structure in the irregularity or bubble) and the background $n_{0}$ (neutral density) are equally important. $\Delta n_{e}$ determines the scintillation strength and if background density $\left(n_{0}\right)$ is more scintillation may be more assuming same percentage of $\Delta n_{e}$. The ratio $\Delta n_{e} / n_{0}$ will also determine the upward velocity of bubbles but irregularities of this scale size are not giving rise to amplitude scintillations. Since $n_{0}$ is large at ano maly crest region scintillations will be stronger there. Many of the characteristics can be explained in terms of changes in $n_{0}$ even though $\Delta n_{e}$ may be the same at different latitudes.

\section{Discussion}

The nighttime ionospheric irregularities are supposed to be first generated in the equatorial F-region and subsequently distinct patches of irregularities are mapped down along the magnetic field lines to latitudes away from dip equator. Factors favorable for generation of irregularities are (i) bottomside electron density gradient (ii) ion-neutral collision frequency at base of the F layer and (iii) the upward drift velocity (Balsley et al., 1972; Rastogi and Woodman, 1978; Abdu et al., 1982, 1983). Although the exact mechanism that triggers the irregularities and subsequent development is yet to be probed for complete understanding, it is believed that these irregularities are constantly in 
2 DECEMBER 1995

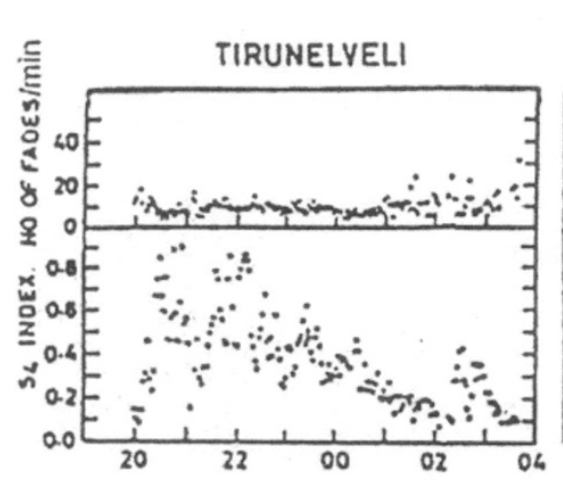

PONOICHERRY

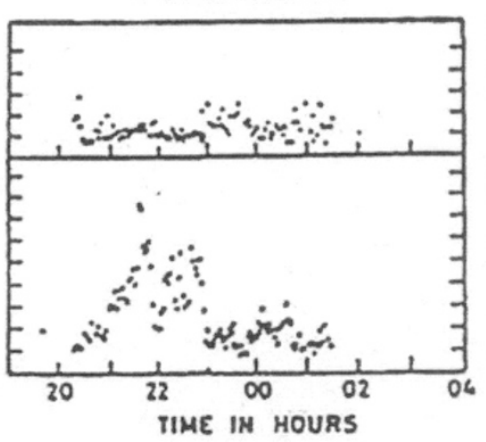

14 DECEMBER 9994 PONDICHERRY

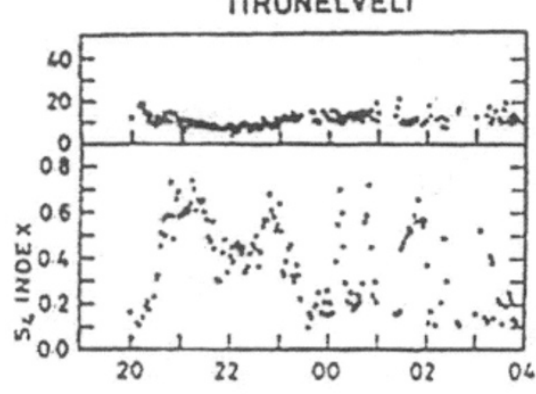

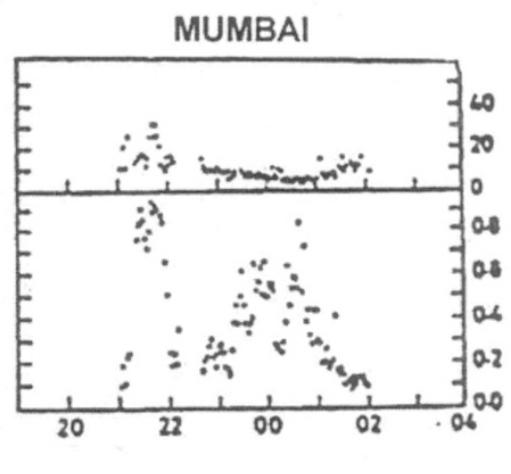

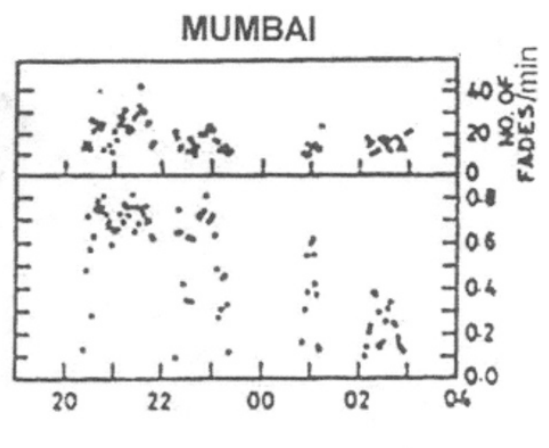

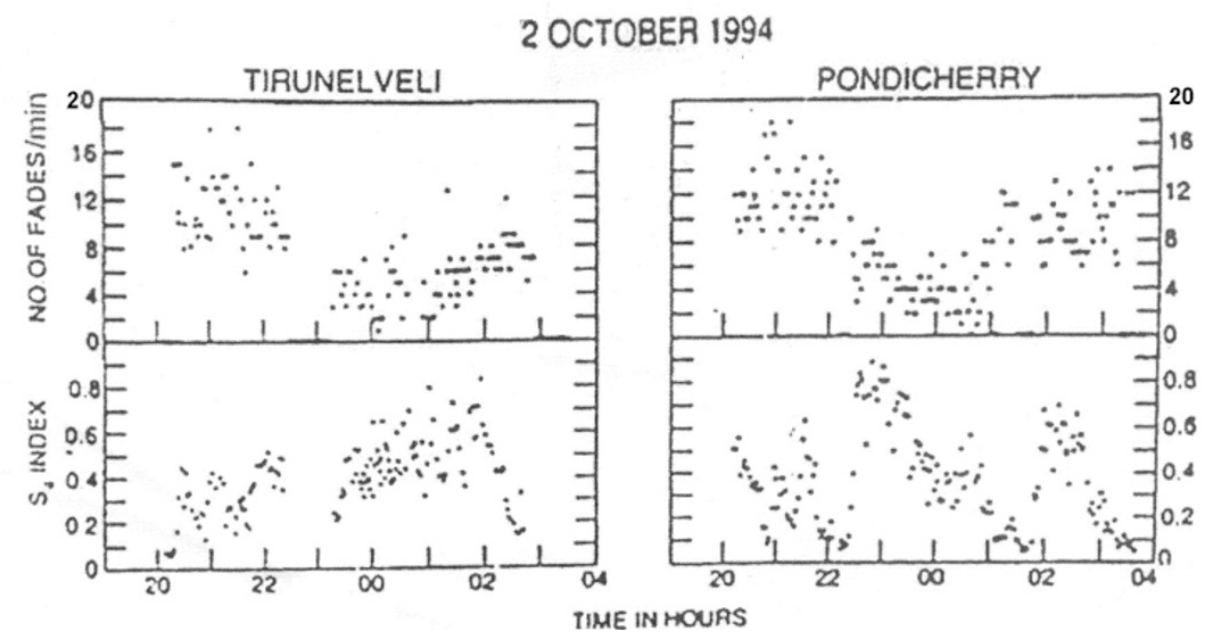

Fig. 5. $S_{4}$ indices and fade rates of the scintillation activity on the nights of 2 December 1995, 14 December 1994 and 2 October 1994.

motion, due to neutral wind and electric fields in the presence of geomagnetic field.

In the equatorial region, electric fields are probably the sources of turbulence. Cole (1971) has shown that in equatorial region, plasma convection generated by E region electric fields will produce $F$ region irregularities with scale size of $\sim 10 \mathrm{~km}$ or greater perpendicular to magnetic field direction. The irregular concentration of metallic ions $\left(\mathrm{Fe}^{2+}\right.$ etc) below $\mathrm{F}$ layer produces variations in integrated Pederson conductivity along equatorial field lines. Then the effect of neutral winds in the region of conductivity structure is to produce electric fields that produce large-scale irregularities $(>10 \mathrm{~km})$. At higher latitudes, electric fields may also be responsible for production of irregularities particularly in and near the auroral oval.

Significant results obtained from different mass plots can be summarized as follows.

1. Spectral index shows a linear increase with $S_{4}$ index. Latitudinal variation in spectral index with $S_{4}$ is not clear from the plots. 


\section{Tirunelveli 27 March 1999}

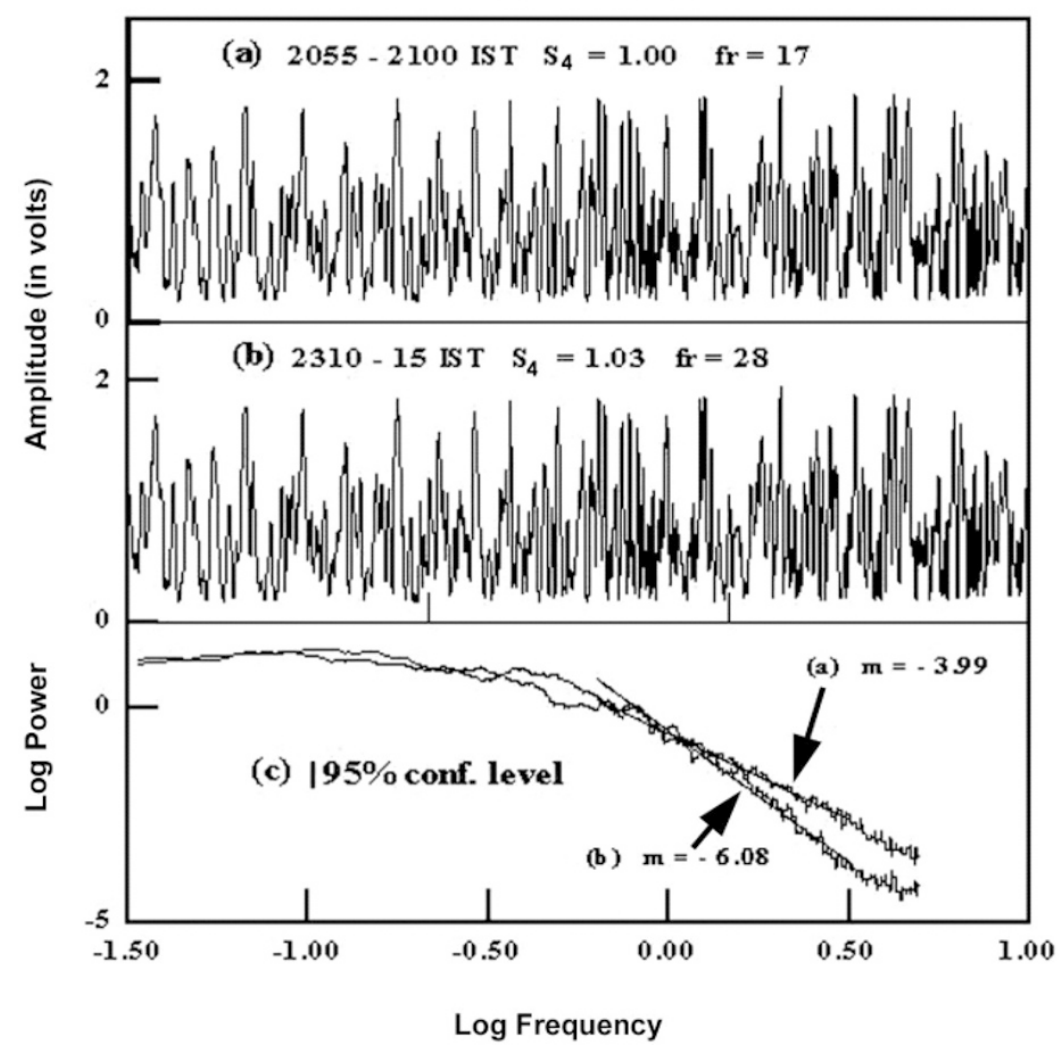

Fig. 6. Amplitude and power spectrum for 27 March 1999 at Tirunelveli (2055 h and $2310 \mathrm{~h}$ ) with same $S_{4}$ index but different fade rates.

Table 4. Percentiles for $S_{4}$ indices for pre-midnight and post-midnight on 9 selected nights.

\begin{tabular}{|c|c|c|c|c|c|c|c|}
\hline \multirow[t]{2}{*}{ Date } & \multirow[t]{2}{*}{ Station } & \multicolumn{3}{|c|}{ Pre-midnight } & \multicolumn{3}{|c|}{ Post-midnight } \\
\hline & & $\mathrm{L}(\mathrm{Q} 1)$ & MED & U(Q3) & $\mathrm{L}(\mathrm{Q} 1)$ & MED & $\mathrm{U}(\mathrm{Q} 3)$ \\
\hline \multirow[t]{2}{*}{$28-12-92$} & Tirunelveli & 0.12 & 0.53 & 0.72 & 0.11 & 0.25 & 0.45 \\
\hline & Mumbai & 0.07 & 0.30 & 0.67 & 0.07 & 0.33 & 0.64 \\
\hline \multirow[t]{2}{*}{$3-4-93$} & Tirunelveli & 0.21 & 0.56 & 0.82 & 0.18 & 0.32 & 0.51 \\
\hline & Mumbai & 0.16 & 0.45 & 0.72 & 0.11 & 0.25 & 0.35 \\
\hline \multirow[t]{2}{*}{$11-6-93$} & Tirunelveli & 0.44 & 0.65 & 0.90 & 0.35 & 0.58 & 0.88 \\
\hline & Mumbai & 0.35 & 0.54 & 0.76 & 0.28 & 0.42 & 0.55 \\
\hline \multirow[t]{2}{*}{$14-9-94$} & Tirunelveli & 0.39 & 0.51 & 0.85 & 0.25 & 0.43 & 0.65 \\
\hline & Mumbai & 0.25 & 0.42 & 0.71 & 0.12 & 0.35 & 0.53 \\
\hline \multirow[t]{2}{*}{$2-10-94$} & Tirunelveli & 0.26 & 0.45 & 0.60 & 0.21 & 0.40 & 0.52 \\
\hline & Pondicherry & 0.22 & 0.42 & 0.66 & 0.16 & 0.33 & 0.59 \\
\hline \multirow[t]{3}{*}{$14-12-94$} & Tirunelveli & 0.28 & 0.44 & 0.55 & 0.17 & 0.27 & 0.51 \\
\hline & Pondicherry & 0.27 & 0.38 & 0.43 & 0.15 & 0.23 & 0.46 \\
\hline & Mumbai & 0.48 & 0.67 & 0.76 & 0.16 & 0.26 & 0.33 \\
\hline \multirow[t]{2}{*}{$30-1-95$} & Pondicherry & 0.39 & 0.48 & 0.66 & 0.25 & 0.33 & 0.58 \\
\hline & Mumbai & 0.25 & 0.33 & 0.55 & 0.15 & 0.25 & 0.42 \\
\hline \multirow[t]{3}{*}{$2-12-95$} & Tirunelveli & 0.35 & 0.46 & 0.53 & 0.13 & 0.21 & 0.31 \\
\hline & Pondicherry & 0.16 & 0.27 & 0.46 & 0.14 & 0.18 & 0.26 \\
\hline & Mumbai & 0.23 & 0.44 & 0.61 & 0.13 & 0.18 & 0.56 \\
\hline \multirow[t]{2}{*}{$19-10-96$} & Tirunelveli & 0.15 & 0.42 & 0.99 & 0.25 & 0.63 & 0.84 \\
\hline & Mumbai & 0.43 & 0.66 & 0.97 & 0.14 & 0.32 & 0.44 \\
\hline
\end{tabular}

2. Spectral index does not show any clear relation with fade rate.
3. $S_{4}$ indices and fade rates are higher during evolution phase of the activity. 
Tirunelveli 21 Sept. 1992

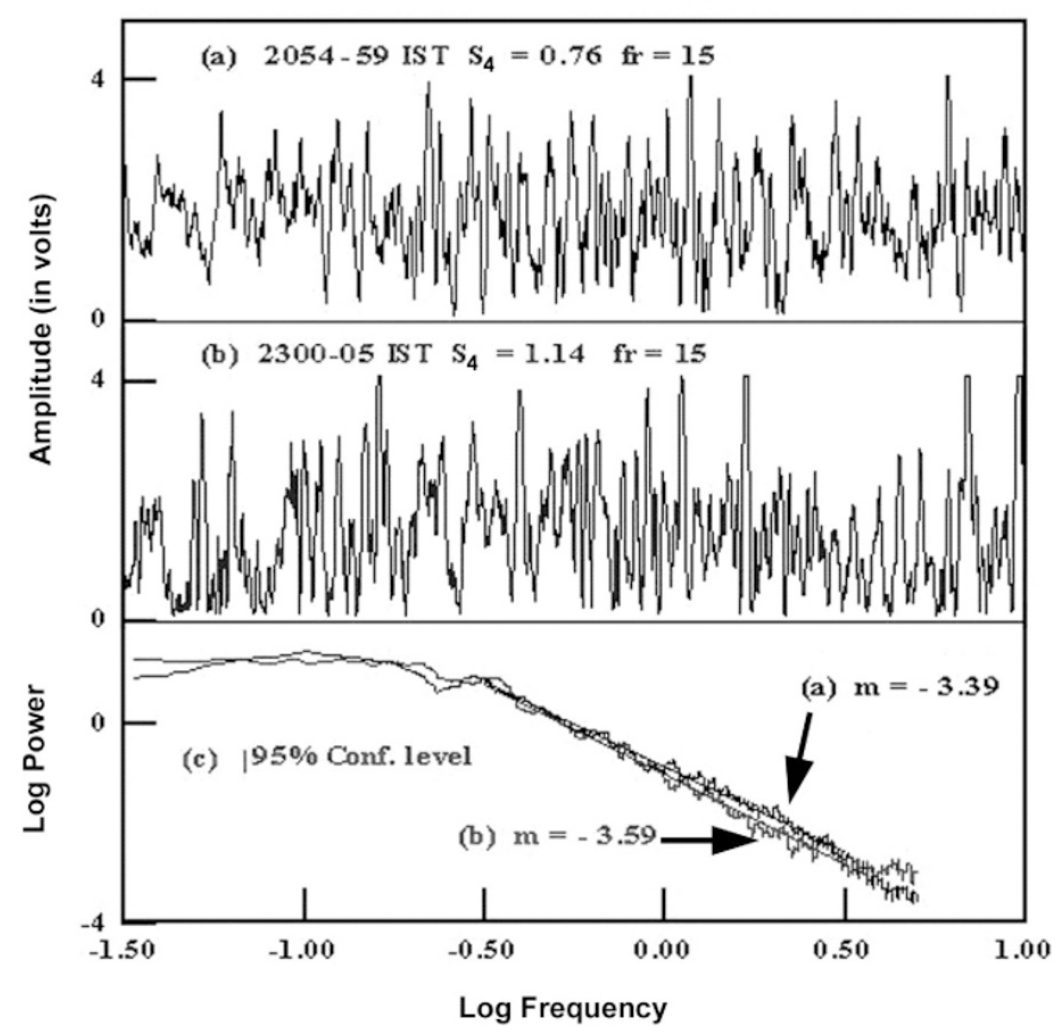

Fig. 7. Amplitude and power spectrum for 21 September 1992 at Tirunelveli (2054 h and $2300 \mathrm{~h})$ with different $S_{4}$ indices but same fade rates.

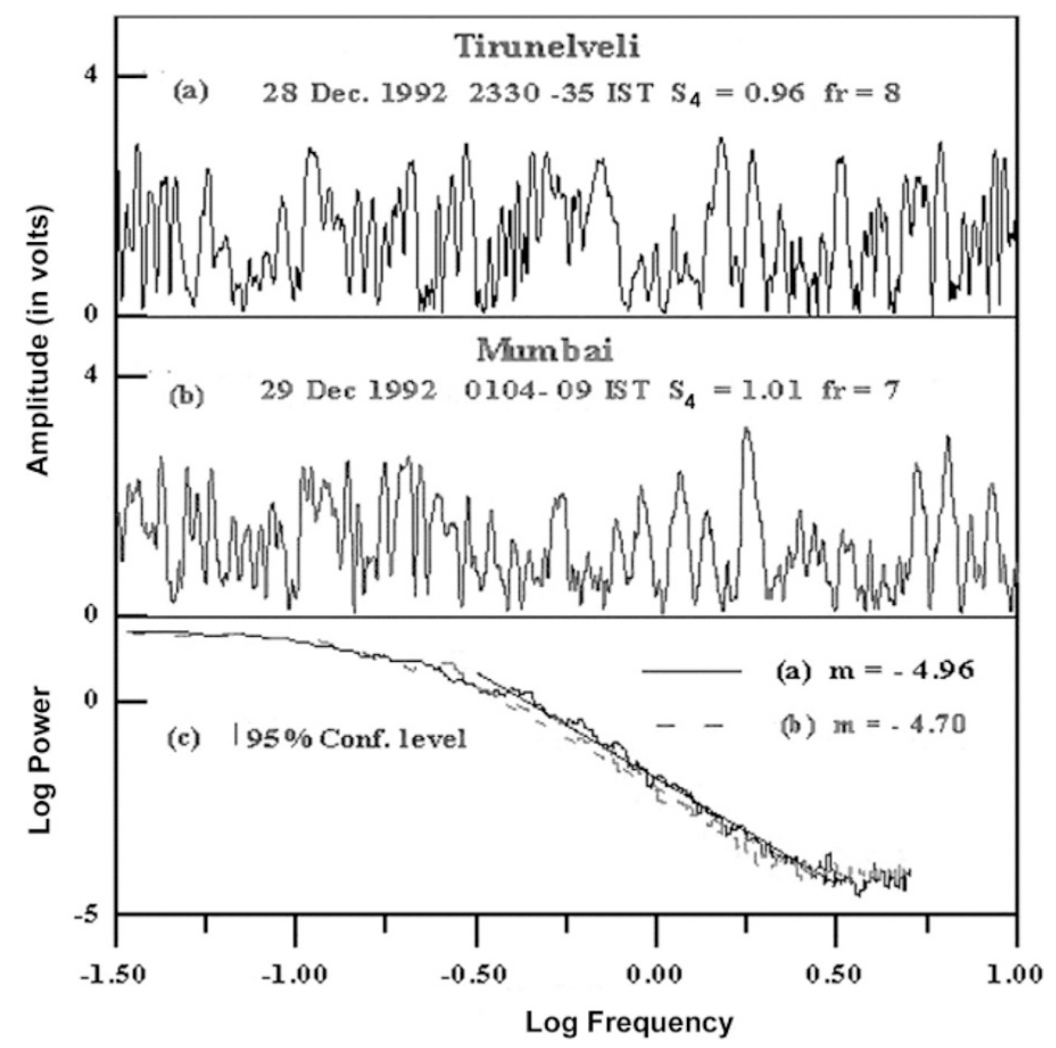

Fig. 8. Amplitude and power spectrum for the 28/29 December 1992 at Tirunelveli $(2330 \mathrm{~h})$ and Mumbai $(0104 \mathrm{~h})$ with same $S_{4}$ index and fade rate. 


\section{MUMBAI 2 DECEMBER 1995 \\ POST-MIDNIGHT $\quad(r=0.58, m=3.54)$}

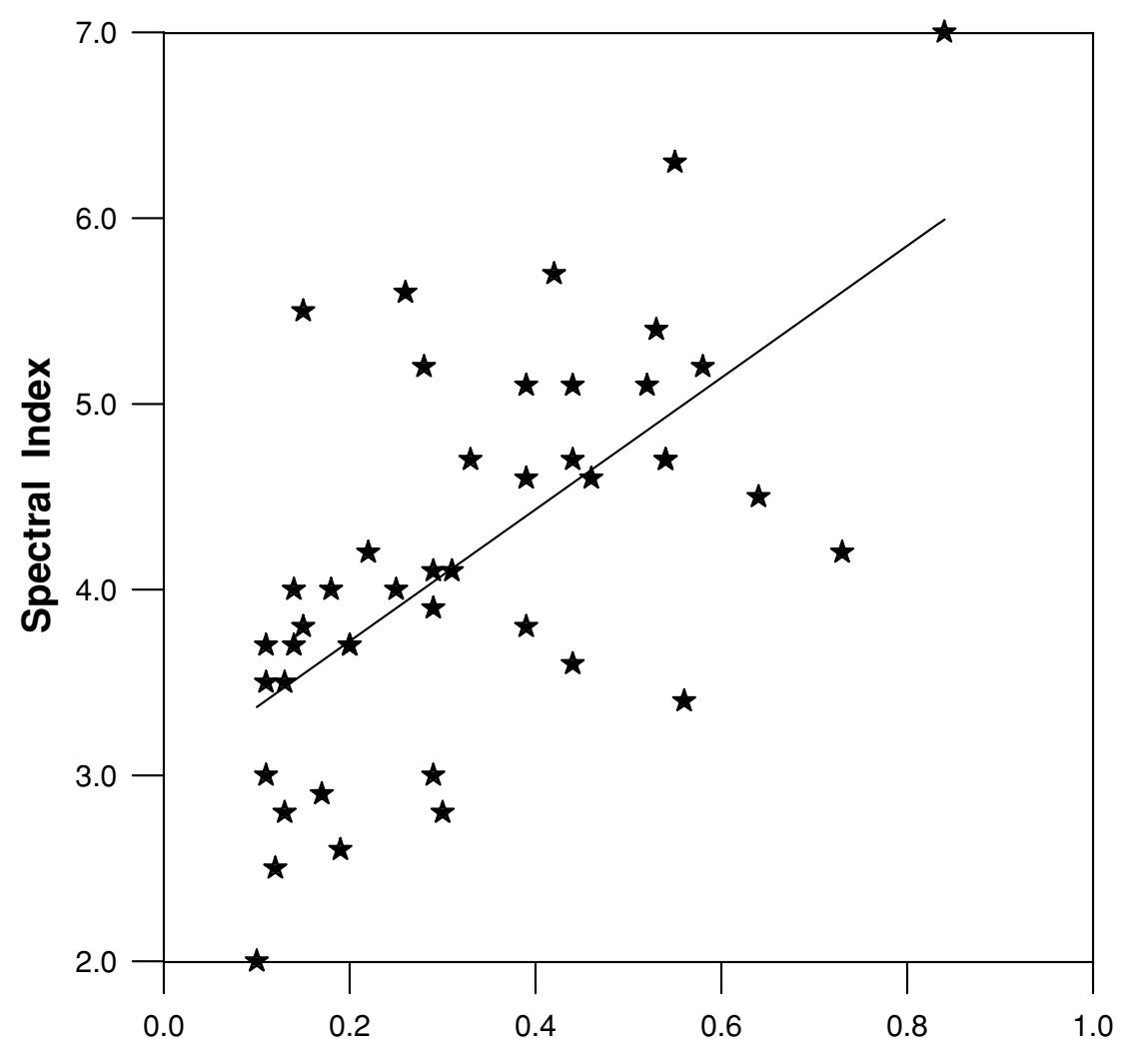

S4 Index

Fig. 9. Variation of the spectral index with the scintillation index $\left(S_{4}\right)$ obtained from the post-midnight scintillation data at Mumbai on 2 December 1995. Correlation coefficient and the average magnitude of spectral slopes are also shown.

4. Auto-correlation interval is noticed to be more at Mumbai than at equatorial region.

5. Spectral slopes are shallower for scintillation during generation-phase of the activity and are steeper towards the decay phase.

6. Correlation distance decreases with increase in the latitude.

In Table 1 are listed the velocities estimated from the Fresnel frequency at three latitudes. Velocity is found to decrease with increase in latitude. Scintillation studies both at high latitudes (Kersley and Chandra, 1984) and at low latitudes (Basu and Whitney, 1983, Chandra et al., 1992) show dependence of the spectral index on the scintillation index. Here we observe that the spectral index shows a linear increase with $S_{4}$ as shown in Fig. 9 for post-midnight data of 2 December 1995 for Mumbai. Linear Correlation Coefficient $(r)$ for this interval works out to be about 0.58 . However during pre-midnight time, there is considerable scatter $(r=0.18)$.

As shown in Fig. 2, a delay of about an hour in onset time of scintillation is seen at Mumbai when compared with equatorial stations. Onset of scintillation is near simultaneous at equatorial stations Tirunelveli and Pondicherry whereas a delayed onset of about 15 minutes to a few hours is seen at Mumbai in all the other cases. The pattern shows that the scintillation producing irregularities are generated near the magnetic equator and then they either expand or propagate towards higher latitudes. Somayajulu et al. (1984) studied scintillation measurements at a meridian chain of few stations in the Indian region. They found that the onset of scintillation at stations where subionospheric points are within $12^{\circ} \mathrm{N}$ magnetic latitude was almost simultaneous but was delayed at a station whose sub-ionospheric point is at $21^{\circ} \mathrm{N}$ magnetic latitude, by between 15 minutes to 4 hours. The delay in onset of scintillation was considered by them to be the time taken by irregularities in their travel from the equator to higher latitudes. Under some favorable conditions the plasma bubbles grow in altitude over the magnetic equator and irregularities associated with these bubbles map down along the geomagnetic field lines to latitudes away from magnetic equator. The mapping of irregularities down the field lines is considered to be nearly instantaneous. As the bubbles rise, the field aligned depleted regions extend to latitudes farther and farther from the dip equator. Somayajulu et al. (1984) concluded that the latitudinal extent of the post-sunset scintillation phenomenon is dependent on the maximum height to which the plasma bubbles develop over the magnetic equator. The 
onset, duration and decay of scintillations at different latitudes would depend on the growth, shape and dynamics of the equatorial plasma bubbles.

As stated earlier, plasma instabilities in the nighttime $\mathrm{F}$ region of the equatorial ionosphere, often give rise to irregularities in the plasma with scale sizes varying from tens of $\mathrm{km}$ down to a fraction of a meter. Effective height of irregularity, which also depends on thickness of irregularity layer, determines the dimension of irregularities that are most effective in causing amplitude scintillation on account of Fresnel Filtration. This Fresnel dimension gets translated into roll-off frequency for power spectrum of weak amplitude scintillation. The spectrum in respect of scintillation follows a power-law variation (Dyson et al., 1974). Scintillation are caused by irregularities having wavelengths equal to or smaller than the Fresnel zone dimension $(\pi \lambda Z)^{1 / 2}$. In view of observed power law variation of the irregularity spectrum, the intensity of irregularities will be relatively small at smaller wavelength. Hence irregularities of the order of the Fresnel dimension will con tribute mostly to scintillation and irregularities of smaller dimension will induce less amplitude fluctuations.

Fade rates are expected to be lower corresponding to irregularities of Fresnel dimension. Higher fade rates on some nights at equatorial stations indicate that the irregularities are dominantly shorter in wavelengths compared with irregularity causing scintillation at Mumbai. As fade rate is directly proportional to size or velocity of irregularities, higher velocity will give rise to faster fading.

Spectrum of electron density fluctuation is mapped-down on the radio waves traversing through the ionosphere. Thus, temporal power spectrum of radio waves scintillation is related to the in-situ spatial spectrum of scintillation producing irregularities in the ionospheric electron density. Traditionally the spectra of the electron density fluctuations along with associated autocorrelation function were assumed to be Gaussian (Briggs and Parkin, 1963). However, the observation of scintillation spectra (Elkins and Papagiannis, 1969; Rufenach, 1972) have shown a power law electron density fluctuation spectrum to be more appropriate. Singleton (1974) has shown that scintillation spectrum indicates that its diffraction pattern is isotropic or nearly so. If the irregularities are Gaussian, the plot of Fourier Spectral Power in $\mathrm{db} V_{s}$ frequency squared should be a straight line for frequencies in excess of Fresnel frequency. On other hand, if irregularities have a power law spatial spectrum, plot of Fourier Spectral Power in db $V_{s}$ Log Frequency should be a straight line above the Fresnel frequency. Comparing two plots Singleton (1974) inferred that the irregularities should have power law nature. Consequently, on the basis of Fourier spectrum of scintillation, a power law irregularity spectrum could be explained from the results presented here.

The power falls off as $f^{-m}$ for frequencies $f$ above the roll off frequency when the irregularities themselves have a power law form $K^{-p}$, where $K$ is the component of the irregularity wave vector perpendicular to the propagation path of the signal. (Bhattacharyya and Rastogi, 1985, 1991). Slope $(m)$ of high frequency asymptotes of log-log plot of scintillation power spectrum is related to 3 dimen- sional power law index $(p)$ for the irregularities by,

$$
p=m-1 \text {. }
$$

Present results indicate that the post-midnight spectral slopes of the irregularities were marginally higher at all the three latitudes when compared to pre-midnight times indicating the decay of shorter wavelength ionospheric irregularities first at all the latitudes at those times. Spectral slopes values were in the range between -1.9 to -5.2 , showing that part of the transitional scale and part of the intermediate scale irregularities were covered on the nights of scintillation.

Chandra et al. (1992) obtained spectral index values in the range of 2 to 6 with mean value of 4 from scintillation measurements on $136.1 \mathrm{MHz}$ at SHAR (dip $13^{\circ} \mathrm{N}$ ) in India. Prakash et al. (1991) reported spectral index values, in scale size 20-200 m, ranging from 1.5 to 4.6 for one-dimensional power spectra of in-situ electron density fluctuations measured by rocket-borne Langmuir probe flown from SHAR. This translates to scintillation spectral index from 2.5 to 5.6. Relationship between the spectral index and spectral power was described by a Gaussian function, which gives a maximum value of 4.43 for spectral index. This would correspond to a maximum $p$ value of 5.43. Since larger $\left(\Delta n_{e}\right)^{2}$ would contribute to stronger scintillation the present results showing steeper spectral slopes with increasing $S_{4}$ index are also consistent with the in-situ results. The increase in the spectral index with scintillation index is also consistent with similar results reported for equatorial scintillation at Ancon and for high latitude stations. Spectral index values were seen to increase with the spectral power $\left(n_{e} / \Delta n_{e}\right)^{2}$ of irregularities. Basu et al. (1980) reported higher values of spectral index at Ascension Island (Anomaly Crest location) as compared to equatorial location (Ancon and Huancayo). However, they stated that the results were not conclusive. Analyzing about 100 scintillation events recorded at Ahmedabad (close to anomaly crest region in India), Vyas and Chandra (1994) gave spectral indices in the range, 1 to 5, with a median value of 2.8. Basu and Whitney (1983) have reported a mean spectral index value of 3.5 for scintillation observed at Ancon, near magnetic equator. Bramley and Browning (1978) reported a mean spectral index value of 4.4 for a mid-latitude station, while Kersley and Chandra (1984) obtained values in the range 2.5-4.8 with mean value of 3.58 for scintillation associated with equator ward edge of the high-latitude scintillations region. The spectral index value of 4 obtained here from the temporal spectra of scintillation would correspond to a one dimensional spectral index value of 3 . In-situ observations obtained from rocket-borne and satellite measurements in the intermediate scale wavelengths $(20 \mathrm{~km}-100 \mathrm{~m})$ give a mean spectral index close to 2.5. Basu et al. (1980) reported a spectral index value of 2.8 for scale sizes less than $1 \mathrm{~km}$ and of 1.5 for scale sizes greater than $1 \mathrm{~km}$ from in situ data obtained from AE-E satellite.

In the present study spectral slopes are varying between -1.9 to -5.2 , which gives spectral index in the range 2.9 to 6.2 corresponding to scale size of $20 \mathrm{~m}-1000 \mathrm{~m}$ for low and equatorial latitudinal regions in India.

The broadening of the spectrum is closely related to cor- 
relation interval (Umeki et al., 1977). The smaller the correlation interval is, the more spectrum broadens. Decorrelation becomes more apparent as frequency decreases. The decorrelation is due to multiple scattering of wave by irregularities. Correlation interval estimated from single site observation of amplitude scintillation is a feature of scintillation phenomenon itself and not of the structure of ionospheric irregularities. Correlation interval, in general decreases rapidly in cases of strong scintillation signifying faster decorrelation of the signal. Table 1 shows autocorrelation interval and corresponding ground decorrelation distance varying from $67 \mathrm{~m}$ to $188 \mathrm{~m}$. From the present study, the autocorrelation intervals are found significantly higher during the post-midnight period at Mumbai when compared to the other two equatorial stations.

The study concludes that scale size distribution of irregularity pertain only to a small part of the measured spectrum which corresponds to irregularities of wavelengths up to several 100 meters. From Table 1, we observe that irregularities with scale sizes close to the Fresnel dimension, which is approximately $1 \mathrm{~km}$ for the $250 \mathrm{MHz}$ signal are most effective in causing amplitude scintillation. Hence any measure of amplitude scintillation, such as the $S_{4}$ index, is determined to a large extent, by the scale size distribution of the longer wavelength $(\geq 1 \mathrm{~km})$ irregularities (Bhattacharyya and Rastogi, 1985)

Large-scale (larger than Fresnel dimension) irregularities give rise to small-scale patterns on the ground. Fremouw et al. (1978) suggested that the equatorial scintillation could have been produced by irregularities having a greater effective height than those at the higher latitudes, thereby giving rise to greater amplitude scintillation for a given level of phase fluctuations.

\section{Conclusion}

The scintillations are stronger and faster in the premidnight as compared to that in the post-midnight period at all the three stations Tirunelveli, Pondicherry and Mumbai. $S_{4}$ index and fade rates are higher during evolution phase.

Autocorrelation interval decreases with increase of irregularity drift speed as also with the increase of $S_{4}$ index. Transverse drift velocity of irregularity is found to vary between $40 \mathrm{~m} / \mathrm{s}$ to $118 \mathrm{~m} / \mathrm{s}$ while ground decorrelation distance varies from $68 \mathrm{~m}$ to $188 \mathrm{~m}$ for the cases taken up in the Indian region.

\section{References}

Aarons, J., Global morphology of ionospheric scintillations, Proc. IEEE, 70, 360-378, 1982.

Abdu, M. A., R. T. De Medeiros, and J. H. A. Sobral, Equatorial spread$\mathrm{F}$ instability conditions as determined from ionosonde observations, Geophys. Res. Lett., 9, 692-695, 1982.

Abdu, M. A., R. T. De Medeiros, J. H. A. Sobral, and J. A. Bittencourt, Spread-F plasma bubble vertical rise velocities determined from spaced ionosonde observations, J. Geophys. Res., 88, 9197-9204, 1983.

Anderson, D. N. and G. Haerendel, The motion of depleted plasma regions in the equatorial ionosphere, J. Geophys. Res., 84, 4251-4256, 1979.

Balsley, B. B., G. Haerendal, and R. A. Greenwald, Equatorial Spread-F: recent observations and new interpretations, J. Geophy. Res., 77, 56255628, 1972.

Banerjee, P. K., R. S. Dabas, and B. M. Reddy, C and L band transionospheric scintillation experiment: Some results for applications to Satellite Radio Systems, Radio Sci., 27(6), 955-969, 1992.
Basu, Su. and S. Basu, Equatorial scintillations, Progress Science ISEA-6, J. Atmos. Terr. Phys., 47, 753-768, 1985.

Basu, S. and H. E. Whitney, The temporal structure of intensity scintillation near the magnetic equator, Radio Sci., 18(2), 263-271, 1983.

Basu, S., J. P. McClure, S. Basu, W. B. Hanson, and J. Aarons, Coordinated study of equatorial scintillation and in situ and radio observations of nighttime F region irregularities, J. Geophys. Res., 85, 5119-5130, 1980

Bhattacharyya, A. and R. G. Rastogi, Amplitude scintillation during early and late phases of evolution of irregularities in the nighttime equatorial ionosphere, Radio Sci., 20(4), 935-946, 1985.

Bhattacharyya, A. and R. G. Rastogi, Structure of ionospheric irregularities from amplitude and phase scintillation observations, Radio Sci., 26(2), 439-449, 1991.

Bramley, E. N. and R. Browning, Mid-latitude ionospheric scintillation of geostationary satellite signals at $137 \mathrm{MHz}$, J. Atmos. Terr. Phys., 40 , 1247-1255, 1978

Briggs, B. H. and I. A. Parkin, On the variation of radio star and satellite scintillations with zenith angle, J. Atmos. Terr. Phys., 25, 339-366, 1963.

Chandra, H., Equatorial spread-F-Recent developments, Ind. J. Radio Space Phys., 19, 215-224, 1990.

Chandra, H., Hari Om Vats, G. Sethia, M. R. Deshpande, R. G. Rastogi, J. H. Sastri, and B. S. Murthy, Ionospheric scintillations associated with features of equatorial ionosphere, Ann. Geophys., 35, 145-151, 1979.

Chandra, H., G. D. Vyas, H. S. S. Sinha, R. N. Mishra, and S. Prakash, Ionospheric scintillation observations from SHAR, J. Atmos. Terr Phys., 54, 167-172, 1992.

Chandra, H. et al., Co-ordinated multistation VHF scintillation observations in India during March-April 1991, Ind. J. Radio Space Phys., 22, 69-81, 1993.

Cole, K. D., Formation of field-aligned irregularities in the magnetosphere, J. Atmos. Terr. Phys., 33, 741-750, 1971.

Dungey, J. W., Convective diffusion in the equatorial F region, J. Atmos. Terr. Phys., 9, 304-310, 1956.

Dyson, P. L., J. P. McClure, and W. B. Hanson, In situ measurements of the spectral characteristics of $\mathrm{F}$ region ionospheric irregularities, $J$. Geophys. Res., 79, 1497-1502, 1974.

Elkin, T. J. and M. D. Papagiannis, Measurement and interpretation of power spectrum of ionospheric scintillation at a sub-auroral location, J. Geophys. Res., 74, 4105-4115, 1969.

Fejer, B. G and M. C. Kelley, Ionospheric irregularities, Rev. Geophys. Space Phys., 18, 401-454, 1980.

Fremouw, E. J., R. L. Leadbrand, R. C. Livingston, M. D. Cousins, C. L. Rino, B. C. Fair, and R. A. Long, Early results from the DNA wide band satellite experiment-complex signal scintillation, Radio Sci., 13, 167-187, 1978 .

Haerendal, G., Report, Max Planck Institute fur Physik und Astrophysik, Garching, West Germany, 1973.

Kelley, M. C. and J. P. McClure, Equatorial Spread-F: A review of recent experimental results, J. Atmos. Ter. Phys., 43, 427-435, 1981.

Kersley, L. and H. Chandra, Power spectra of VHF intensity scintillations from $\mathrm{F}_{2}$ and $\mathrm{E}$ region ionospheric irregularities, J. Atmos. Terr. Phys., 46(8), 667-672, 1984

Krishnamoorthy, K., C. R. Reddy, and B. V. Krishnamurthy, Nighttime ionospheric scintillations at the magnetic equator, J. Atmos. Terr. Phys., 41, 123-134, 1979.

Ossakow, S. L., Spread-F theories-a review, J. Atmos. Terr. Phys., 43, 437-452, 1981 .

Pathak, K. N., R. D. Jivrajani, B. Mathew, H. P. Joshi, and K. N. Iyer, Study of ionospheric scintillations near the crest of equatorial anomaly in India using digital data base, Ind. J. Radio Space Phys., 24, 138-150, 1995

Pathan, B. M., P. V. Koparkar, R. G. Rastogi, and D. R. K. Rao, Dynamics of ionospheric irregularities producing VHF radio wave scintillations at low latitudes, Ann. Geophys., 9, 126-132, 1991.

Prakash, S., S. Pal, and H. Chandra, In-situ studies of equatorial spread-F over SHAR-steep gradients in the bottomside F-region and transitional wavelength results, J. Atmos. Terr. Phys., 53(10), 977-986, 1991.

Rastogi, R. G., Solar cycle effect in radio wave scintillations at Huancayo, Ind. J. Radio Space Phys., 11, 215-221, 1982.

Rastogi, R. G. and R. F. Woodman, VHF radiowave scattering due to range and frequency types of equatorial spread-F, J. Atmos. Terr. Phys., 40, 485-491, 1978.

Rastogi, R. G., H. Chandra, and M. R. Deshpande, Equatorial radio scintillations of ATS-6 radio beacons: Phase II Ootacamund 1975-76, Ind. 
J. Radio Space Phys., 11, 240-246, 1982.

Rufenach, C. L., Power law wavenumber spectrum deduced from ionospheric scintillation observations, J. Geophys. Res., 77, 4761-4772, 1972.

Singleton, D. G., Power spectra of ionospheric scintillations, J. Atmos. Terr. Phys., 36, 113-133, 1974.

Somayajulu, Y. V., S. C. Garg, R. S. Dabas, Lakha Singh, T. R. Tyagi, B. Loknadhan, S. Ramkrishna, and G. Navneeth, Multistation study of nighttime scintillations in low latitudes: Evidence of control by equatorial F region irregularities, Radio Sci., 19, 707-718, 1984.

Sushil Kumar, A. K. Gwal, P. V. S. Rama Rao et al., Co-ordinated observations of VHF scintillations in India during February-March 1993, Ind. J. Radio Space Phys., 29, 22-29, 2000.
Taur, R. R., Ionospheric scintillations at 4 to $6 \mathrm{GHz}$, COMSAT Tech. Rev., 3, 145-163, 1973.

Umeki, R., C. H. Liu, and C. K. Yeh, Multifrequency spectra of ionospheric amplitude scintillations, J. Geophys. Res., 82, 2752-2760, 1977.

Vyas, G. D. and H. Chandra, VHF scintillation and spread-F in the anomaly crest region, Ind. J. Radio Space Phys., 23, 157-164, 1994.

Woodman, R. F. and S. Basu, Comparison between 'in-situ' spectral measurements of equatorial $\mathrm{F}$ region irregularities backscatter observations at $3 \mathrm{~m}$ wavelength, Geophys. Res. Lett., 5, 869-872, 1978.

S. Banola (e-mail: sridhar_banola@yahoo.com), B. M. Pathan, D. R K. Rao, and H. Chandra 